\title{
O SELF COMO CENTRO DE AÇÃO EM JAMES E WINNICOTT
}

Claudia Passos-Ferreira

Claudia Passos-Ferreira

Psicóloga clínica, bolsista de

Pós-Doutorado, recém-doutora da Faperj do Programa de Pós-Graduação em Saúde Coletiva (IMS/Uerj). Mestre e doutora em Saúde Coletiva pelo IMS /

Uerj, especialista em Saúde Mental e Saúde Mental Infantil pelo Instituto Municipal Philippe Pinel/RJ.
RESUMO: Trata-se de investigar a noção de self agente em James e Winnicott. Em James, examinamos o elemento descritivo que constitui o self. Em Winnicott, exploramos a teoria explicativa sobre a emergência do self. A perspectiva de Winnicott é apresentada aqui como a pré-história do self jamesiano. A concepção de James é análoga ao self integrado winnicottiano, concebido como uma posição corporificada resultante da ação do organismo no campo experiencial. A combinação das duas abordagens resulta na noção de self como fluxo de identidade que emerge da interação com os outros no espaço transicional.

Palavras-chave: Self, ação, ontogênese, interação, Winnicott, James.

ABSTRACT: The self-agency in James and Winnicott. Our goal is to investigate the notion of self-agency in James and Winnicott. With James, we examine the descriptive element of what constitutes a self. With Winnicott, we explore his explanatory theory on self-emergence. Winnicott's perspective is presented here as the prehistory of the Jamesian self. James's conception of self is similar to the Winnicottian integrated self that is an embodied position that emerges from the organism's actions at the experiential field. The blend of the two approaches leads to the idea that the self is a flux of identities emerging in interaction with others in the transitional space.

Keywords: Self, action, ontogenesis, interaction, Winnicott, James. 


\section{O SELF AGENTE EM JAMES E WINNICOTT}

Em "A permanência de William James" (2000), Putnam defende a atualidade e abrangência do pensamento de James e recupera sua filosofia interessada em 'como viver'. A ideia de aproximar autores como James e Winnicott vem menos de uma afinidade conceitual e mais da preocupação comum com questões relativas a 'como viver'. Ambos construíram uma imagem naturalista do ser humano, que, parafraseando Putnam (2000), alimenta fomes reais. Tanto James quanto Winnicott foram inspirados por problemas relacionados ao mundo em que viviam, e tentaram fazer do pensamento que desenvolveram um elemento para a vida, uma Weltanschauung.

Pode-se argumentar que James foi mais longe que Winnicott. Com certeza, a obra do primeiro é mais abrangente do ponto de vista filosófico. A tentativa de relacioná-los traz o perigo de fazer comparações e extrair conclusões que reduzam o alcance do pensamento analisado. James foi um pensador que inaugurou uma escola filosófica de pensamento que se opunha aos modelos metafísicos tradicionais, que buscavam garantias para o pensamento em verdades fundacionais. Defendia a inserção de sua filosofia na tradição do pragmatismo, definido como um método para resolver disputas metafísicas. Apoiado em seu empirismo radical, propunha o pluralismo como a forma permanente do mundo, abdicando de encontrar um ponto de vista superior absoluto. O pluralismo de James é comprometido com a existência de diferentes pontos de vista que servem a diferentes propósitos. Seu esforço conceitual intentou criar uma ontologia que compatibilizasse a crença nas teses darwinianas com a crença no livre arbítrio. Essa tensão resultou na imagem naturalizada do homem como ser de ação livre.

Winnicott, por sua vez, ocupou-se menos da tarefa de criar uma nova forma de pensar. Buscou reformular as concepções psicanalíticas sobre como se constitui o psiquismo, para fornecer um instrumental teórico que justificasse suas experiências clínicas. Sua intenção foi construir uma imagem do psiquismo que não se resumisse à dinâmica pulsional edipiana. Winnicott não apresentou suas ideias de forma sistematizada e não estava preocupado com o refinamento teórico do debate conceitual. Seu foco de interesse era a adequação de seus conceitos à prática clínica, pecando, muitas vezes, em precisão conceitual e rigor teórico. Foi devido ao esforço de compreender o que observava em seus pacientes que criou sua metáfora sobre o que somos e como vivemos.

A riqueza da aproximação repousa no fato de que um pensamento parece ampliar o outro. Explicitando melhor, a ontologia de James oferece uma imagem naturalizada do ser humano, mas não formula uma explicação a respeito de como este se constitui subjetivamente. James fornece uma descrição sobre o que é o self. A preocupação primeira de Winnicott é formular uma teoria explicativa sobre como surge o self a partir da experiência do bebê. Ele se dedica a compreender 
o processo de constituição do psiquismo naturalizado. Formula a ontogênese do psiquismo, que pode ser considerada como uma pré-história que explica a emergência do self jamesiano. O self, como definido por James, é o self saudável winnicottiano que experimentou o processo de desenvolvimento emocional na direção de sua integração.

Contudo, se, no sentido mais amplo, ambos apresentam uma concepção de self que queremos preservar, no âmbito conceitual mais restrito parece haver discrepâncias que tornam difícil a comparação termo a termo. Vejamos o termo 'consciência'. A conceituação winnicottiana toma como ponto de partida o psiquismo freudiano dividido em consciente e inconsciente, e se detém pouco sobre os fenômenos da consciência. Por outro lado, James não trabalha com a hipótese do inconsciente sistemático, e admite somente a ideia de uma consciência secundária. Ao contrário de Winnicott, James se ocupou do estudo da consciência a tal ponto que, para ele, o problema mente-corpo era o problema da consciência. Isso se reflete na forma como cada um define o self.

O self jamesiano guarda a divisão tradicional do 'eu empírico' (o self que é conhecido) e o 'eu sujeito' (o self conhecedor), mesmo que seja para questionar os problemas oriundos da divisão. Em Psychology: briefer course (1892/1992a), James reformula as noções de autoconsciência e identidade da pessoa ao descrever o 'self conhecedor'. Para escapar da metafísica que concebia o self como um 'olho interno' que espelha representações privilegiadas, e evitar os problemas conceituais da divisão kantiana 'ego empírico’ x ‘ego transcendental’, James postulou a existência de um fluxo da consciência. A noção de fluxo da consciência é contrária à hipótese de um princípio transcendental de unidade, ou uma 'alma como meio arranjador', no qual possamos ancorar a noção de identidade da pessoa. Mas, se o self conhecedor é o fluxo de consciência, como explicar a identidade do self? Para James, a identidade da pessoa, a experiência de continuidade, ou seja, a sensação de que continuamos os mesmos, é dada pelo momento em que o self se apropria de um fluxo de consciência produzido anteriormente. Em suas palavras:

"Quem se apropria do último self se apropria do self anterior ao último, pois tudo aquilo que o possuído possui, o possuidor possui. É impossível descobrir qualquer característica verificável na identidade pessoal que não contenha este esquema, é impossível imaginar como qualquer princípio transcendente de unidade (caso houvesse um princípio ali) poderia conduzir as coisas a qualquer outro resultado, ou sendo conhecido por qualquer outro fruto, a não ser essa produção de um fluxo de consciência o qual cada parte sucessiva deve conhecer, e conhecendo, aproximar-se de si mesma e adotar, tudo aquilo que veio antes, - assim correspondendo ao representativo de um fluxo inteiro do passado com o qual não é sábio estar identificado." (JAMES, 1892/1992a, p.199) 
O contraste com Winnicott é evidente. Winnicott nunca se interessou pelo debate metafísico e jamais enveredou pela investigação sobre a consciência. Sua concepção de psiquismo resulta em uma descrição do self que permite abandonar disputas metafísicas, no melhor espírito da tradição pragmática. Para Winnicott, o sentido de continuidade do self não é garantido por uma entidade orquestradora das experiências. Ao contrário, o sentido de continuidade subjetiva é algo que ocorre na experiência de descontinuidade. O self integrado resulta das vivências de continuidade e descontinuidade, que não cessam de se processar, pois essa experiência faz parte da própria dimensão humana. O self winnicottiano apresenta, desde o início, uma divisão baseada no modo pelo qual o self se relaciona com o mundo e interage no espaço externo.

A combinação dessas abordagens parece frutífera. James derruba as escadas metafísicas tradicionais que levam à noção de substância da alma, e Winnicott constrói uma imagem do psiquismo na qual o self não é mais a entidade alojada no interior dos corpos ou acima desses — o self é simplesmente uma posição corporal resultante da ação do organismo no campo experiencial que, tanto para Winnicott quanto para James, é o ambiente regido por leis darwinianas. Winnicott cria a ontogênese do sujeito a partir do que foi descrito por James, sobre a forma como agimos no mundo. Para Winnicott, nossos vínculos com o outro não são apenas expressão de nossa natureza — mais do que isso, é a forma como nos constituímos. James descreve um self naturalizado constituído no processo de desenvolvimento normal e adaptado ao contexto da sociedade ocidental, em particular do homem americano. A combinação dessas noções permite formular uma concepção sobre o homem como ser de natureza cuja existência do self resulta de sua interação com o ambiente, ou seja: o 'eu sou' está sempre relacionado ao contexto de vida em que se dá a experiência transicional. E se o self é a resultante do processo de constituição subjetiva, seu contorno final é sempre provisório e relativo ao espaço externo no qual vive. O self é um fluxo de identidade que evolui no espaço transicional.

Apresentarei a gênese do self em Winnicott e a noção de self em James, mostrando como ambos formulam a subjetividade constituída como uma posição, um centro de ação no campo da experiência externalizada.

\section{A ONTOGÊNESE NATURALISTA DE WINNICOTT}

As teorizações de Winnicott dividem-se em dois eixos: 1) a concepção naturalizada do indivíduo, na qual aborda o desenvolvimento do self e do mundo interno a partir da realidade transicional; 2) a concepção psicológica do indivíduo, na qual aborda a constituição psíquica, utilizando a divisão entre falso self e verdadeiro self, que é concebida como uma divisão constitutiva presente 
em toda experiência humana. Privilegio, nessa seção, o primeiro eixo no qual Winnicott concentra as teses sobre a constituição do espaço transicional e a relação com o psiquismo. No primeiro eixo, os parâmetros de correlação com as ideias de James são frouxos e precários, já que o mesmo não se ocupou da gênese do psiquismo. O segundo eixo, que diz respeito à concepção psicológica do indivíduo, é de fértil comparação com as ideias de James sobre o self, e será utilizado na terceira seção.

Winnicott (1965b/1990) compreende a constituição subjetiva como um processo natural, a ser acompanhado por um ambiente relativamente não intruso que se ajuste ao processo. Para que o processo ocorra, é necessário um ambiente que se adeque ao ser em desenvolvimento, oferecendo condições para que emerja uma mente relativamente autônoma, com capacidade autonarrativa, de deliberação e ação inovadora. O processo de desenvolvimento ocorre no sentido da não integração para integração, propiciado pela imersão do organismo num ambiente adequado, com um objetivo teleológico da espécie biológica a cumprir: a constituição de um self. Dessa experiência, resultam a constituição do mundo interior com capacidade imaginativa, a mente com capacidade intelectiva, e o self que instaura o sentimento de unidade e continuidade de existência e a capacidade de ação criativa.

O processo de desenvolvimento emocional se origina do 'psique-soma' indistinto (WINNICOTT, 1954a/1993). O conceito de 'psique-soma' é usado de forma imprecisa. Às vezes, é identificado ao esquema corporal; em outras, afirma-se que "a psique habita o soma”. Este conceito expressa uma constituição psíquica que, apesar de ser uma substância única, experimenta sensações corpóreas e constrói representações sobre elas. Expressa uma experiência emocional que emerge do corpo em desenvolvimento. Não são necessariamente substâncias ontologicamente distintas, e, portanto, não sustentam um dualismo de substâncias. São manifestações ou propriedades diferenciadas da mesma realidade material, que expressam duas formas de observar o desenvolvimento do indivíduo, ora privilegiando o aspecto emocional, ora a corporeidade.

A psique se refere à elaboração imaginativa das funções corpóreas, sensações e percepção, ou seja, é a representação mental do que é vivenciado corporalmente. É do processo de inter-relação do psique-soma que emerge a mente, com capacidade de consciência e simbolização, que será posteriormente enriquecida pela aquisição da linguagem. Para Winnicott (1954a/1993), a mente não tem um lugar específico no corpo. A mente é ontologicamente distinta da materialidade cerebral, apesar de admitir a necessidade da integridade do cérebro para o exercício da atividade mental. Porém, o desenvolvimento da mente não se restringe a aspectos inerentes ao organismo. A integração mente-psique-soma é algo a ser conquistado no processo de desenvolvimento, e não um dado a priori. Uma falha 
no ambiente pode produzir distorções tais, que o indivíduo experimenta a mente como estando localizada em uma parte do corpo, desintegrada ou em oposição ao psique-soma. O desenvolvimento da mente é variável e depende de um ambiente que favoreça a continuidade da existência e o desenvolvimento do self.

Para que haja a emergência do self é necessário que o psique-soma esteja fusionado ao ambiente perfeito. O que proporcionará ao bebê o sentimento de ser um self alojado no corpo é sua inserção num ambiente suficientemente bom. O ambiente perfeito e facilitador se origina a partir da identificação da mãe ao bebê. A consistência do cuidado materno como meio para o crescimento capacita o bebê a começar a existir, a ter experiência, a construir o ego, a guiar instintos, e a se deparar com as dificuldades inerentes à vida (PHILLIPS, 1998). É fundamental que a mãe-ambiente seja suficientemente adaptada aos fatores constitucionais do bebê, às demandas do bebê, para que a continuidade da existência não seja perturbada. A mãe suficientemente boa é a que oferece ao bebê o "holding", o toque e a apresentação do objeto (WINNICOTT, 1965a/2001).

A imagem winnicottiana da origem humana é, portanto, a da unidade mãe-bebê, num estado fusional. Ao nascer, ou até mesmo antes do nascimento, o bebê e a mãe não existem separadamente. Nascemos imersos no ambiente. O momento de fusão mãe-bebê é de absoluta dependência do bebê aos cuidados da mãe. O bebê e a mãe se encontram fundidos por uma "afinidade egoica". O bebê não existe ainda como pessoa com experiências separadas da mãe-ambiente. Esse estado é 'puramente subjetivo', uma área de ilusão, cujo correlato emocional é a experiência de onipotência. Se o desenvolvimento precoce é satisfatório, a criança cria, fora de seu desejo, a mãe que está pronta para ser encontrada. É como se a mãe-suficientemente-boa pertencesse a ele. Como a criança se desenvolve do estado de dependência absoluta da mãe para o de relativa independência, a mãe começa a sair do estado de preocupação primária, fazendo com que a criança comece a experimentar a desilusão. É uma desilusão para o bebê descobrir a mãe como real e além de seu controle mágico. A contínua adaptação da mãe ao bebê assegura que essas experiências estejam no limite de sua crescente tolerância. É esperado e até desejado que a mãe comece gradualmente a falhar em sua adaptação, favorecendo um contato do bebê, em pequenas doses suportáveis, com um mundo que resiste a ele, que oferece obstáculo.

Após terem sido estabelecidas a criatividade primária e a capacidade de ilusão, é possível para o bebê alcançar um estágio de independência relativa pela via do uso de seu primeiro objeto não eu: o objeto transicional (WINNICOTT, 1953c/1993). A sequência da experiência pode ser descrita como segue. Inicialmente, o bebê age sobre o objeto. Em seguida, o objeto resiste à onipotência criativa. Quando o indivíduo encontra a resistência, há um reflexo e ele volta para si. Depois disso, ele age, ou melhor, tem um ato criativo, e, assim, 
constitui a realidade externa e modifica a interna. Ao agir no mundo, uma parte da mente se externaliza e fica do lado de fora, e há uma modificação do mental. Em suma, o processo do desenvolvimento consiste na crescente capacidade para tolerar o contínuo e altamente sofisticado processo de ilusão-desilusão-reilusão por todo o ciclo da vida. É assumido que a tarefa de aceitação da realidade nunca é completada, que nenhum ser humano está livre do esforço de relacionar realidade interna e externa (WINNICOTT, 1971/1975). O fenômeno transicional torna possíveis as transições iniciais fundamentais da subjetividade para a objetividade, de estar fundido com a mãe para ser algo separado dela. O objeto transicional é sempre uma combinação, mas fornece uma terceira alternativa, idiossincrática e criativa.

Winnicott imagina, portanto, que o desenvolvimento emocional se dirige à conquista de uma experiência tridimensional, a saber, realidade interna, externa, e transicional. O espaço transicional, na ausência de vocabulário que melhor o defina, é descrito como "uma ponte entre o mundo interno e o externo", "hiato entre o interior e o exterior” (WINNICOTT, 1971/1975), reforçando a ideia de um interior e exterior que existem isoladamente e que seria necessário imaginarmos formas de unificá-los, de relacioná-los. A noção de espaço transicional precisa ser entendida como o espaço a partir do qual se constrói a interioridade. Portanto, mundo interno e mundo externo não precisam de pontes, pois são apenas metáforas conceituais que facilitam na descrição da constituição da identidade da pessoa. Essas metáforas separam realidades que se interpenetram e se diferenciam, conforme nossa forma de estar no mundo. É nesse sentido que Winnicott afirma que a tarefa de adaptação à realidade não é apenas uma fase a ser ultrapassada. É um trabalho contínuo da existência humana. O espaço transicional é uma área intermediária de experimentação para a qual tanto a realidade interna quanto a vida externa contribuem, e ela existe como um lugar de repouso para o indivíduo engajado na perpétua tarefa de manter a realidade interna e externa separadas e, ao mesmo tempo, inter-relacionadas. A área da ilusão “é o lugar em que vivemos”, onde se passa a experiência cultural.

A pesquisa winnicottiana descreve o modo como se desenvolvem a mente e a identidade da pessoa, do ponto de vista da psicogênese do indivíduo. Winnicott concebe a emergência do indivíduo singular, cuja ação criadora é fruto da experimentação na área de ilusão, marcada pela tradição cultural. Apesar de sublinhar a importância do código cultural como algo que forma a constituição subjetiva, sua descrição inclui a capacidade de invenção e surgimento do novo, que interessa preservar. 


\section{O SELF TRIDIMENSIONAL DE JAMES}

James não se preocupou em precisar conceitos como 'self' e 'eu'. Faz um uso frouxo dos termos, o que causa certa confusão conceitual, pois usa o termo 'eu’ para partes do self com funções diferenciadas. Por outro lado, ao manter o mesmo termo, o autor enfatiza que a divisão expressa aspectos variados de um único self total. Em The Principles of psychology (1890/1992a), apesar de o interesse estar voltado à investigação da consciência e pensamento, dedicou um capítulo à definição de self, intitulado “The self”. No texto, James enfatiza que, apesar de ser uma unidade ou totalidade, o self possui aspectos distintos. A diferença central é entre o eu que se dá conta da sua existência — o eu da autoconsciência - e o eu que age — o eu empírico. Privilegio aqui as conceituações acerca do 'eu empírico'.

O eu empírico é o self como 'objeto que pode ser conhecido’. James descreve o ‘eu empírico' em dois eixos: o eixo dos constituintes e o das emoções e ações. Inter-relaciona esses eixos, fazendo as emoções e ações variarem conforme o constituinte do eu que está sendo focalizado.

O primeiro eixo é o que constitui o eu. É composto pelos 'eu material', 'eu social' e 'eu espiritual'. James estende os limites espaciais do eu, para torná-lo um 'eu ampliado', que inclui tanto o 'eu corpóreo' quanto o 'eu extracorpóreo'. O eu é não apenas o seu próprio corpo, mas também suas possessões. O 'eu material' é tudo aquilo que provoca um sentimento de pertencimento. Inclui o corpo como a parte mais íntima, mas também roupa, família, casa, coleções, propriedades e possessões. A perda de uma possessão é vivida como estreitamento da personalidade do eu, como destruição parcial de algo do eu. Parte da depressão frente à perda de possessões pode ser explicada pelo sentimento de propriedade que torna os objetos possuídos uma parte do eu.

O 'eu social' é o reconhecimento dos pares. James endossa a tese sociobiológica de que somos seres gregários, que gostamos de ser vistos por nossos companheiros e que temos a propensão inata para sermos conhecidos favoravelmente por nossa espécie. A tendência ao reconhecimento social da espécie faz com que o indivíduo tenha tantos eus sociais quantos indivíduos o reconheçam e conservem mentalmente uma imagem sua, e tão diversos quantos sejam os grupos de pessoas cujas opiniões lhe interessam. Para James, “o eu social mais peculiar de cada indivíduo se acha na mente de quem se é amado” (1890/1922a). James afirma que o 'eu social' é como a imagem do eu aos olhos da própria comunidade.

O 'eu espiritual' é o conjunto dos estados de consciência, capacidades e disposições psíquicas do eu tomadas concretamente. O eu espiritual é o lugar provisório do sentido da atividade, e é experimentado como a porção mais central do self. Os outros componentes parecem externos. Para James, o self da autoconsciência parece ser a parte mais central de nós mesmos, porque quando o 
self se pensa como pensador e toma a si próprio como objeto de seu pensamento, todos os seus demais componentes parecem ser posições relativamente externas. Algumas capacidades são experimentadas como mais externas que outras. Por exemplo, as emoções e desejos nos parecem mais íntimos que as sensações; as decisões volitivas parecem mais íntimas que os processos intelectuais. A porção central do 'eu espiritual' são os estados de consciência mais sensivelmente ativos. O núcleo do self é o sentido da atividade que caracteriza certos estados internos. Todos os estados que possuem a qualidade de parecer ativos apresentam uma peculiar internalidade que daria o sentido de atividade, indo de encontro a outros elementos da experiência. A centralidade parece ser dada pela intencionalidade dos estados. Explicitando melhor, o 'eu espiritual' parece funcionar como um centro gravitacional, cuja centralidade e internalidade não são dadas a priori, mas sim pela intencionalidade pressuposta pelo estado mental.

O segundo eixo diz respeito aos sentimentos e emoções do eu e às ações a que conduzem, em relação a cada um dos constituintes do eu. As emoções estão relacionadas à autoapreciação. James distingue dois tipos de autoapreciação: a autocomplacência, que são os sentimentos de orgulho, vaidade, autoestima, arrogância; e o autodescontentamento, que são os sentimentos de modéstia, humildade, desconfiança, vergonha, desprezo pessoal. Ao contrário do associacionismo que concebe as emoções como fenômenos secundários originários da dinâmica prazer-desprazer (sendo a autossatisfação a representação do prazer, e a vergonha, a do desprazer), James concebe as emoções como primárias, ou seja, são expressões de nossa natureza, não são secundárias a outro fenômeno. Como fenômenos primários, haveria certo tom médio de autoapreciação inerente a cada pessoa, e independente das razões objetivas (prazer e desprazer) que podem ocasionar a satisfação ou descontentamento. Para James, a autossatisfação e o autodescontentamento são emoções primitivas, próprias de nossa natureza, com expressões fisionômicas particulares, que podem aparecer sem causa determinante adequada e racional, ou serem provocadas pela boa ou má posição ocupada no mundo. Essas emoções conduzem a dois campos de ação: a busca de si mesmo e a autoconservação. Essas ações abarcam os impulsos instintivos referentes a cada constituinte do eu:

O cuidado do 'eu corporal'. A autopreservação corporal inclui todas as ações e movimentos reflexos úteis para a alimentação e a defesa. São ações úteis provocadas por emoções primitivas.

O cuidado do 'eu social'. A busca pelo autointeresse social inclui ações que se orientam para a amabilidade e o dom de fazer amigos, e expressam o desejo de agradar, de atrair admiração e notoriedade, emulação e inveja, amor pela glória, influência e poder. Os impulsos de autointeresse social são desejos naturais da espécie. 
O cuidado do 'eu espiritual'. O autointeresse espiritual inclui os impulsos na direção do progresso psíquico, quer seja intelectual, moral ou espiritual no sentido estreito.

James propõe um self total — que não deve ser confundido com self totalizado, fechado - que reúne aspectos diferenciados: um aspecto espacial, que são os contornos e apresentações variadas do eu; um funcional, que é o funcionamento emocional do eu; e outro, experiencial, que são as ações experimentadas pelo eu. Todos esses aspectos podem ser alterados pelo contexto, tempo e perspectiva pela qual observamos o self.

O self jamesiano é um arranjo tridimensional composto pelo 'eu material', 'eu social' e 'eu espiritual'. Essas dimensões do self são seus contornos espaciais, suas interações sociais e suas ações volitivas. Em cada lado do prisma observamos uma dimensão distinta do self, que se altera de acordo com o contexto da experiência que acontece em uma dada temporalidade. O centro do self é o centro gravitacional que oscila em conformidade com a experiência. O centro não é uma resultante do efeito combinatório de seus diversos eus. A centralidade para James é um efeito do fluxo de consciência, é uma função da unidade da consciência que iluminaria, a cada momento, aspectos diferenciados desse prisma. O campo da consciência é um centro circundado por uma franja que escurece o que está fora. No primeiro momento, o centro funciona numa direção, e as margens, em outra; no instante seguinte, o que outrora era margem subjuga o centro e torna-se ela mesma o centro. A identidade da pessoa e sua atividade de pensamento, em qualquer tempo, são o centro. Mas o self completo é o campo todo com todas as possibilidades subconscientes e identitárias.

James sugere uma forma de interação entre as dimensões do 'eu empírico', que é a hierarquia dos eus. Haveria uma ordenação dos diferentes eus individuais de uma pessoa a partir da interação do eu com o contexto em que vive. Na escala hierárquica proposta por James, o eu corporal está no fundo, o eu espiritual está no mais alto e, entre eles, os eus materiais extracorpóreos e os vários eus sociais. Isto reflete a educação moral da espécie, segundo a qual aprendemos a subordinar os eus mais baixos aos eus mais altos, de acordo com um juízo de valor. Em muitos casos, a emoção que nos move é a perseguição de um eu social ideal, que se torna digno de aprovação de um companheiro de juízo mais elevado. Este eu social é uma espécie de espectador ideal que constitui parte essencial da consciência. Em cada gênero do eu material, social, espiritual, distinguimos entre o atual, o remoto e o potencial. Na visão de James, de todos esses eus mais amplos, o 'eu social potencial' seria o mais interessante por causa de sua conexão com nossa vida religiosa e moral.

Projetamos vários 'eus empíricos', vários prismas potenciais, no início de nossas vidas. Isso dá origem ao que James chama de rivalidades e conflitos 
entre os diversos 'eus'. Ao longo da vida, somos obrigados, pela necessidade, a selecionar e favorecer um dos eus empíricos, abandonando o resto. Mas, para tornar um deles real, o resto deve ser, de algum modo, suprimido. Todos os outros selfs tornam-se irreais. Assim, o sentimento próprio, nossa autoestima, depende inteiramente do que desejamos ser e fazer. Isto é determinado pela razão entre nossas existências reais, sucessos e supostas potencialidades. Por isso, James afirma que nenhuma ameaça ou apelo pode mover um homem, a menos que afete um de seus eus potenciais ou reais. Somente isso pode pressionar a vontade de um homem.

\section{O SELF AGENTE}

A noção de 'self agente' captura tanto o 'eu empírico' de James quanto o 'self criativo' de Winnicott. A atividade como experiência é fundamental para o 'self agente', pois o self é uma posição no campo da experiência. O 'self agente' é concebido desde o primeiro movimento de existência como a atividade da própria experiência da vida, como, por exemplo, no processo de respiração enfatizado por James.

Proponho três dimensões de análise: a externalização corporal; a interação social; e o sentimento de continuidade.

1. Em relação à externalização corporal do self, há duas questões: uma ontológica e outra descritiva. O debate sobre a ontologia do self é o problema mente-corpo. Em Winnicott, não encontramos reflexões acerca da ontologia mente-corpo. Tudo o que afirmamos sobre sua ontologia é uma tentativa de enquadrá-lo dentro das posições existentes no campo das teorias da mente. Reconhecemos na terminologia winnicottiana uma tentativa de superação do dualismo mente-corpo. Uma tentativa frustrada, pois o termo psique-soma mantém o uso de expressões distintas para algo que, de um ponto de vista ontológico monista, deveríamos conceber como único. Winnicott parece afirmar que há uma única substância com propriedades distintas. Isso aproxima sua hipótese ontológica da Teoria do Duplo Aspecto de Spinoza, que rechaça o dualismo de substâncias. Esta teoria afirma haver uma única substância, mas reconhece um dualismo de propriedades da substância.

James, ao contrário, apresenta formulações sobre o problema mente-corpo buscando oferecer uma resposta às disputas metafísicas tradicionais. Como mostra Flanagan (1998), encontramos em James um resquício dualista, principalmente em seus escritos iniciais. Apesar da recusa em aderir ao dualismo cartesiano, James formula um tipo de dualismo que envolve um compromisso com a interação entre o físico e o mental. Todas as afirmações sobre as correlações entre o físico e o mental devem ser tomadas como se envolvessem a crença de que 
para cada evento mental particular existe um evento cerebral correspondente. O tipo de interacionismo dualista que James concebe é uma forma ambivalente de dualismo de substância, o qual precisará combinar com seus pressupostos darwinianos. Todavia, os esforços de James no plano ontológico podem ser considerados apenas uma intuição primeira do que foi posteriormente desenvolvido pelo naturalismo pragmático acerca do que é o ser humano (RAMBERG, 2004).

Ambos tentam apoiar-se numa ontologia do ser que dê conta da existência humana como um organismo adaptado ao seu ambiente com capacidade de autonarrativa, consciência de si e ação criativa, escapando assim das oposições tradicionais mente-corpo, interno-externo. Winnicott e James acreditam numa ontologia que favoreça a imagem de um self naturalizado que surge no ambiente externo.

Em relação à descrição do self externalizado, tanto Winnicott quanto James concebem um self cuja centralidade não seria dada pelos contornos do corpo, nem teria uma localização cerebral. James é explícito ao afirmar que nós somos o que possuímos, e, antecipando a intuição winnicottiana, trata o self como uma matéria oscilante: o corpo ora é uma parte do eu, ora é simplesmente eu. Para James (1890/1992a), o eu no sentido amplo “é o resumo de tudo o que ele pode chamar de seu”, e que afeta o eu com as mesmas emoções. Contudo, é somente com Winnicott que fica esclarecido como podemos ter limites tão plásticos. Winnicott mostra que constituímos o nosso 'eu' a partir da experiência de não integração no espaço transicional, quando nos deparamos com o que é 'não eu’. O 'não eu' é aquilo que resiste e faz oposição ao eu. Ao contrário de James, Winnicott guarda uma diferença importante entre o eu e suas possessões. Uma possessão pode vir a ser reconhecida como parte do self em algum momento da experiência. Todavia, a diferença entre o eu e suas possessões é fundamental. A possibilidade de o eu possuir algo é posterior a sua definição de self. O 'eu sou' precede ao 'eu tenho'. Para Winnicott, o sentimento de posse, do qual deriva o sentimento de perda de uma possessão só é possível no momento em que surge o self integrado, que é uma aquisição do processo de desenvolvimento emocional. O self integrado surge da primeira experiência externalizada, e não de uma vivência prévia privatizada. É necessário que se constitua um sentimento de self, que não está dado a priori, no espaço transicional da relação com o outro, para que a pessoa se reconheça em suas ações intencionais. Só assim é possível descrever um ser humano em ação. A potência criativa inata necessita que se constitua a identidade da pessoa para que possamos ver ação onde antes havia movimento. É necessário que se configure a realidade interna, que permita a encenação e representação da ação. A ação criativa visa alterar o mundo, e se realiza na área disponível de manobra, no espaço para o inédito, para o imprevisível. 
2. Em relação ao tópico da interação social do self, o 'eu social' jamesiano, suas emoções e ações, assemelha-se ao falso self winnicottiano. Ambos apresentam essa dimensão do self como a dimensão fundamental da existência humana, mas diferem na forma como imaginam sua constituição. Apoiado no naturalismo, James parece adepto à tese sociobiológica que explica nossos comportamentos com base em impulsos inatos, identificando comportamentos de busca de interação social e reconhecimento social como expressão de tendências biológicas. Sua descrição assume como instinto gregário comportamentos típicos da cultura ocidental, como aspiração a fama e honra. No entanto, se deixamos de lado os reducionismos de sua biologia datada, podemos conceber o 'eu social' como aquele que só se define a partir de sua posição no campo de experiências de seu contexto social, ou seja, o 'eu social' só é, só existe, no espaço da externalidade que, no caso de James, é o contexto de vida americano de fins do século XIX.

A diferença conceitual para Winnicott, nesse aspecto, é importante. Se, para James, o reconhecimento social é uma necessidade inata a ser satisfeita e o não reconhecimento causa sofrimento, pois é vivenciado como uma punição ou um castigo, para Winnicott essa dimensão é constitutiva da experiência da alteridade. Winnicott entende o não reconhecimento como uma experiência de enlouquecimento. Precisamos de um outro que nos faça holding e oposição, que nos reconheça, para que haja o processo de constituição do self. É necessária a presença de um outro real, que é a mãe suficientemente boa winnicottiana, que instaure o espaço transicional para que surja um sentido de self. O self só existe na interação, pois resulta da internalização de algo que foi primeiro externo. Portanto, o mecanismo de constituição do self ocorre sempre na dimensão da externalidade.

O self externalizado é o falso self, que está relacionado às condutas sociais e à repetição das regras culturais que regulam as dinâmicas da interação social. O falso self tem uma natureza defensiva, que é ocultar e proteger o verdadeiro self. Segundo Winnicott, há um continuum de organização, de apresentação do falso self, com graus saudáveis ou patológicos. O falso self apresenta um funcionamento reativo. No encontro com o objeto que faz oposição ou frustra, reage criando em si um comportamento que imita, que representa, a interação social. Assim, o falso self é o lugar das identidades egoicas e de onde partem as ações volitivas. O falso self é o centro da ação pragmática, é o ordenador da vontade.

O falso self de Winnicott assemelha-se ao 'eu social' de James, e podem ser nomeados de 'self pragmático'. Os dois apresentam uma vida emocional e agem no mundo em função de suas interações sociais. O self pragmático é aquele que se constitui em função de sua ação no mundo e que se reconhece a partir da posição que ocupa no contexto social. O conteúdo do self pragmático é dado por seus contatos com o mundo dos objetos. E é por meio dessa experiência que o 
self pragmático constrói suas diversas identidades, seus diversos 'eus', que, no dizer de James, são tantos quantos forem os grupos sociais que interagimos.

3. O último tópico refere-se ao sentimento de continuidade do self. Esse aspecto do self é central para ambos os autores. Em relação a James, diz respeito à noção de que o self é o sentido da atividade dos estados internos. Nesse sentido, a intenção da ação seria elaborada no espaço de consciência do self antes mesmo de se tornar uma ação externalizada. Rejeitando a ideia de que haveria uma intencionalidade intrínseca (RAMBERG, 2004) que precederia a emergência do self, proponho que o sentido da atividade do self surge no momento em que agimos, sugerindo um arranjo permanente do self. Ou seja, o que reconhecemos como self está diretamente relacionado a nossa ação no mundo. O self não é prévio à atividade, ele se constitui no exercício da ação.

Podemos aproximar o eu espiritual jamesiano ao gesto espontâneo ou a criatividade originária de Winnicott que expressa o verdadeiro self. O verdadeiro self é a experiência de sentir-se real, da continuidade de existir. É o que dá sentido de realidade ao self. A força vital originária do verdadeiro self, expressão do vitalismo winnicottiano, é uma força que, ao encontrar uma oposição ou obstáculo no meio externo, subjetiva-se, expressando-se de forma criativa ou agressiva. É necessário haver uma oposição do ambiente para que se desenvolva o potencial criativo, pois não é possível saber como o ambiente irá se comportar. O ambiente é imprevisível. Como vimos, o verdadeiro self tem um gesto espontâneo inicial. Ao encontrar uma resistência, há um reflexo e o verdadeiro self se volta para si. Depois disso, há um ato criativo, e, assim, o verdadeiro self constitui a realidade externa e modifica a interna. Ao agir no mundo, uma parte da mente se externaliza e fica do lado de fora, e outra parte é internalizada, resultando na modificação da mente. A interiorização da mente é necessária para a estabilização do self, pois o sentimento de continuidade da existência depende da internalização das ações externas do self sobre o meio.

\section{CONCLUSÃO}

A noção de agentividade aqui apresentada difere da noção do self como um centro ordenador da vontade e das ações do eu. Tradicionalmente, o eu seria a agência racional que não apenas guiaria o comportamento humano, mas seria responsável pelo arranjo das informações cognitivas e perceptivas. Na acepção de Winnicott e James, o self agente não é uma estrutura prévia à experiência, ou um eu solipsista que funciona como um 'quartel general' controlador de ações e comportamentos; o self agente é o centro da ação que se constitui na própria experiência. Considero que a combinação das duas abordagens resulta na noção de self como fluxo de identidade que emerge da interação com os outros no espaço 
transicional. Assim, a aquisição do sentimento de continuidade que caracteriza a experiência de ser um self só é possível na interação social e por meio da externalização corporal. Portanto, o self agente é uma projeção cognitiva situada em contextos físicos e sociais que começa a fabricar sua mente por meio de sua ação corporal, antes mesmo da aquisição da linguagem e da capacidade narrativa.

Recebido em 17/5/2011. Aprovado em 22/8/2011.

\section{REFERÊNCIAS}

DENNETT, D. (1996) Kinds of minds: toward an understanding of consciousness. Nova York: Basic Books.

. (1995) Elbow room. Cambridge: MIT Press.

FLANAGAN, O. (1998) "Consciousness as a pragmatist views it", in Putnam, R. A. The Cambridge Companion to William James. Cambridge: Cambridge University Press.

JAMES, W. (1992a) Writings 1878-1899. Edited by Gerald Myers, New York: The Library of America.

. (1992b) Writings 1902-1910. Edited by Gerald Myers, New York:

The Library of America.

KARNAC, H. (2000) A linguagem de Winnicott. Rio de Janeiro: Revinter.

PASSOS-FERREIRA, C. (2000) “A causalidade psíquica em Freud”. Dissertação de Mestrado Programa em Pós-Graduação em Saúde Coletiva, Instituto de Medicina Social, Universidade do Estado do Rio de Janeiro, Rio de Janeiro.

PHILlIPS, A. (1988) Winnicott. Cambridge: Harvard University Press.

PUTNAM, R. A. (1998) The Cambridge Companion to William James. Cambridge: Cambridge University Press.

PUTNAM, H. (2000) Pragmatism: an open question. Oxford \& Cambridge: Blackwell.

RAMBERG, B. (2004) Naturalizing idealizations: pragmatism and the interpretivist stance. Contemporary Pragmatism, 2(1), 1-63.

WINNICOTT, D. W. (1945d/1993) “Desenvolvimento emocional primitivo”(1945), in Da pediatria à psicanálise. Rio de Janeiro: Francisco Alves. (1954a/1993) "A mente e sua relação com o psique-soma" (1949), in D Da pediatria à psicanálise. Rio de Janeiro: Francisco Alves.

. (1958b/1993) "Agressão e sua relação com o desenvolvimento emocional” (1950), in Da pediatria à psicanálise. Rio de Janeiro: Francisco Alves.

. (1953c/1993) "Objetos transicionais e fenômenos transicionais" (1951). in Da pediatria à psicanálise. Rio de Janeiro: Francisco Alves. 
(1971/1975) O brincar \& a realidade. Rio de Janeiro: Imago.

(1965b/1990) O ambiente e os processos maturacionais. Porto Alegre:

Artes Médicas.

(1965a/2001) A família e o desenvolvimento individual. São Paulo: Martins Fontes.

Claudia Passos-Ferreira

cpassosferreira@gmail.com 